\section{Bush plans expansion of science and computing}

\section{$\$ 1,000$ million for high-performance computing - Pre-college science gets top education priority}

\section{Washington}

BUOYED by the success of this year's $\$ 1,000$ million US global warming initiative, President George Bush is planning to introduce similar initiatives in highperformance computing and science education in his January budget request for 1992, said D. Allan Bromley, the President's science adviser, in an intervicw last week. In the case of the computing initiative, the President is expected to request more than $\$ 150$ million above the $\$ 500$ million the federal government is already spending on high-performance computing, a category that includes supercomputers, high-speed net-works and advanced software development.

Funding will rise to over $\$ 1,000$ million by 1997 , according to a report* issued last year by the White House Office of Science and Technology Policy (OSTP). Bromley said the new initiative will largely follow the recommendations of the report.

Extra funds are also expected to accompany the launch of the science-education initiative. Although the size of the increase is still under negotiation, administration officials say that total funding will be well over the $\$ 1,800$ million the federal government now spends.

Both initiatives will combine existing efforts of participating federal agencies, as well as create new programmes, Bromley said. Like the massive global warming initiative, which was the first to mould the research programmes at many agencies to fit one set of specific priorities, the computing and education initiatives will have their goals and agendas set by the Federal Coordinating Council on Science, Education and Technology (FCCSET), a body led by Bromley and made up of top officials from all the science-related federal agencies.

A FCCSET initiative is best for "areas that don't fit comfortably into one or a few agencies, but across many agencies, as well as those that don't fit comfortably into a single discipline", Bromley said. "There is also some presumption that such initiatives should receive increased funding." This year, Congress granted most of the administration's request for a 57 per cent ( $\$ 375$ million) increase for global warming research over last year.

Encouraged by such success, Bromley said he now considers FCCSET initiatives a "major policy instrument". Future in-

* The Federal High Performance Computing Program. Office of Science and Technology Policy. September 8, 1989 itiatives may be announced in material science and technology and in biotechnology, he said.

\section{High-performance computing}

The high-performance computing initiative has been in the making for several years, says Charles Brownstein. National Science Foundation (NSF) acting assistant director for computer and information science and engineering. It will combine

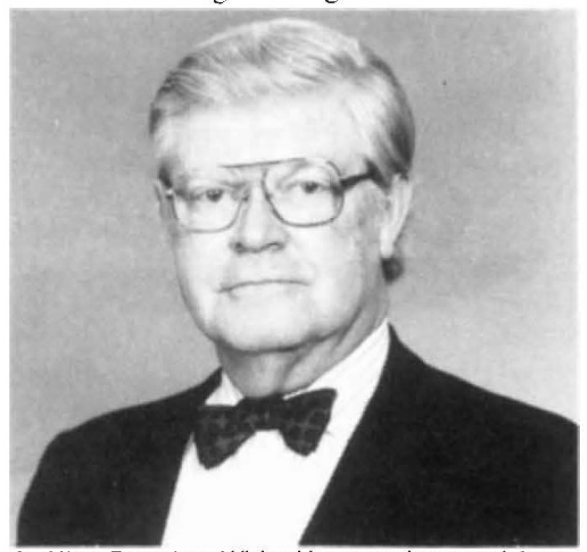

D. Allan Bromley, White House science adviser.

the NSF's four supercomputer centres, the Defence advanced Research Projects Agency's Strategic Computing initiative the "hypercube" computing initiative at the National Aeronautics and Space Administration's (NASA) laboratories and the Department of Energy's (DoE) climate-change computing and magneticfusion computing programmes (see Nature 344, 277; 22 March 1990). A total of eight agencies will participate, Brownstein says.

Top priorities, according to Brownstein, will include:

- Designing new computer hardware and operating systems, emphasizing "scaleable" parallel-processing technology that can be applied to a wide range of highperformance computers. By the end of the five-year programme, researchers hope to have computers whose performance is measured in the "tera-op" range; that is, trillions of operations per second, or 1,000 times more powerful than today's computers

- Putting these machines in centres such as the DoE's National Laboratories, the NSF supercomputer centres and NASA research centres. All these machines will also be connected to national networks such as the Internet and NSFNet.

- Expanding existing networks and online databases. The current NSFNet 'backbone' will soon be at T3 speed - 45 megabits per second. But expansions that will be part of the new initiative will "vastly expand connectivity to literally hundreds of higher-education and precollege education centres as well as industry", Brownstein says.

- Ten per cent of the initiative's budget will go to "basic research and human resources" - projects aimed at individual investigators, to encourage scientists to take advantage of the high-performance computing

\section{Education and human resources}

The education initiative also reflects the priorities of Congress, although it is solely an administration effort. Because Congress, which has historically ranked education higher than has the White House, tends to appropriate more for education than the President requests, "there's been a proliferation of band-aid programmes"; small projects that may be worthy, but do not necessarily contribute to national priorities, says David Sanchez, NSF assistant director for education: "There are a lot of little programmes that need looking at", he says.

Even with the new initiative, which will be spread across 11 agencies, the federal government's spending will represent less than 10 per cent of the total US education budget, notes Luther Williams, assistant director for education at NSF. At present, federal spending is only 6 per cent of the total, meaning that its role is "catalytic", says Williams. That makes it all the more important that all US science education efforts point the same way, he says.

The top priority for the new initiative will be on pre-college education, which accounts for two-thirds of the NSF budget.

Christopher Anderson BSE

\section{First non-UK case}

\section{Geneva}

THE first European case of the cattle disease bovine spongiform encephalopathy (BSE) outside the United Kingdom and the Irish republic has been recorded in a six-year-old cow from the Jura mountains in northwest Switzerland. Two more suspected Swiss cases are being examined.

Peter Gasner, director of the Swiss veterinary office, says the infected cow was Swiss-born, but it is not known whether it had consumed animal feed imported from the United Kingdom. Cattle feed containing offal from infected animals was banned in the United Kingdom after being identified as the most likely mode of BSE transmission. The Swiss case will renew speculation that the disease has occurred undiagnosed elsewhere; Gasner finds it "unbelievable" that BSE is absent from the rest of the European continent.

Peter Aldhous 